\title{
INFECTIOUS DISEASES - JUNE 1997
}

\section{TRENDS}

$\mathrm{U}$ seasonably high numbers of Ross River virus infection were reported with onset in April (Figure 1). This end-of-season surge is likely to be due to increased mosquito activity brought about by late summer rains around the mid NSW coast (stretching from the Hunter though to the Illawarra). Reports of 45 cases of Ross River virus infection among residents of Wentworth Area for the year sparked media attention. Preliminary investigation by Public Health Unit (PHU) staff in Areas around Sydney suggests that most cases acquired infection in non-urban Areas. Figure 2 highlights Areas of the State most at risk of this infection and places media concerns about the risk to Sydney residents in context.

A doubling in the expected number of cases of meningococcal disease reports with onset in April reflects increased activity in some Areas of the State, notably in the Wentworth Area (see the May issue of the NSW Public Health Bulletin). The release of the National Health and Medical Research Council's Guidelines for the control of meningococcal disease in Australia provides timely and useful recommendations for clinicians and public health practitioners.

Reports of pertussis, although declining, remain above historical averages (Figure 1). Since 1993, case reports of pertussis in NSW have remained high. May notifications increased from some Areas, notably from the Hunter and Northern Sydney Areas.

\section{HISTOPLASMOSIS}

A healthy 27-year-old man was admitted to a Sydney hospital on May 30, 1997 and diagnosed with the rare fungal infection histoplasmosis.

Histoplasmosis causes an illness that affects various systems of the body, primarily the lungs. Symptoms are variable but can last months, and the infection can be fatal. Histoplasmosis is common in many parts of the world (including North America), but rare in NSW. It is likely to be present in bat guano (faeces). A handful of past NSW cases has been associated with caving.

The patient went spelunking in Grill Cave and Fossil Hogans Cave in Bungonia National Park (near Goulburn) with several other people in December 1996. Reports suggest the man may have had intimate contact with bat guano while in one of the caves, indicating that there would be minimal risk to other cave visitors unless they had direct exposure to guano.

The National Parks and Wildlife Service (NPWS) reports that up to 10,000 people enter these caves each year. There is no evidence that people entering the caves are at significant risk for histoplasmosis unless they ingest or directly inhale bat faeces.

Central Sydney Public Health Unit staff have identified other people who entered the caves with the patient and interviewed them about exposures and illness. Some of these individuals are being tested for evidence of infection.

\section{HEPATITIS A OUTBREAK LINKED TO A SYDNEY RESTAURANT}

By June 30, 23 cases of hepatitis A linked to attendance at a popular restaurant (restaurant $A$ ) had been notified to the South Eastern Sydney Public Health Unit. Of the cases, 11 (48 per cent) were female and ages ranged from 7 to 48 years. All cases reported onset of jaundice since June 2. Nineteen cases reported eating at the restaurant on Mother's Day (May 11), and four reported eating there the following Sunday.

PHU staff inspected restaurant A on June 12. Blood was taken from all 20 food handler employees identified by the proprietor as working on Mother's Day, and all tested negative for recent hepatitis $\mathrm{A}$ infection.

On June 18, 1997, the Health Department issued a warning through the media advising that patrons who attended the restaurant since May 1 may be at risk for hepatitis $\mathrm{A}$, and that patrons who developed any symptoms of illness should contact their medical practitioner. The restaurant voluntarily closed for business until the source of infection was identified.

A case-control study was conducted by Public Health Officer trainees, PHU and NSW Health Department staff. The study included 22 cases and 72 diners who had eaten at the restaurant on Mother's Day, identified from restaurant A's reservation list. Preliminary analysis shows that all cases, but only 53 ( 74 per cent) controls, reported eating prawns at the restaurant $(p<0.05)$. Cases reported consumption of no other common food items.

The prawns served at restaurant A in June were traced to a batch of frozen fresh-water prawns imported from Burma. In response to the epidemiological and food inspection findings, the importer voluntarily recalled the remaining prawns from the distributors and restaurant $\mathrm{A}$ was cleared to reopen to the public.

Detection of hepatitis A virus from food samples associated with illness is difficult. This is because:

$$
\begin{array}{l|l}
\text { - it is not possible to sample the food that has been } \\
\text { eaten; and } \\
\text { the laboratory techniques employed (using } \\
\text { polymerase chain reaction [PCR] techniques) are } \\
\text { still experimental. }
\end{array}
$$

While a positive test will help confirm epidemiological findings, a negative test does not necessarily provide useful information. PCR testing failed to detect hepatitis A in a sample of restaurant A's leftover prawns.

\section{INFLUENZA A AND B RETURN}

In 1996, NSW and other parts of Australia recorded an increase in influenza A (H3N2) activity which peaked in July. Little influenza B activity was reported. The consultation rate for influenza-like illness among patients of sentinel general practices in NSW peaked at 2.5 per cent - well below epidemic levels. 


\section{FIGURE 1}

REPORTS OF SELECTED INFECTIOUS DISEASES, NSW, 12 MONTHS TO APRIL 1997, BY MONTH OF ONSET (WITH HISTORICAL COMPARISON)
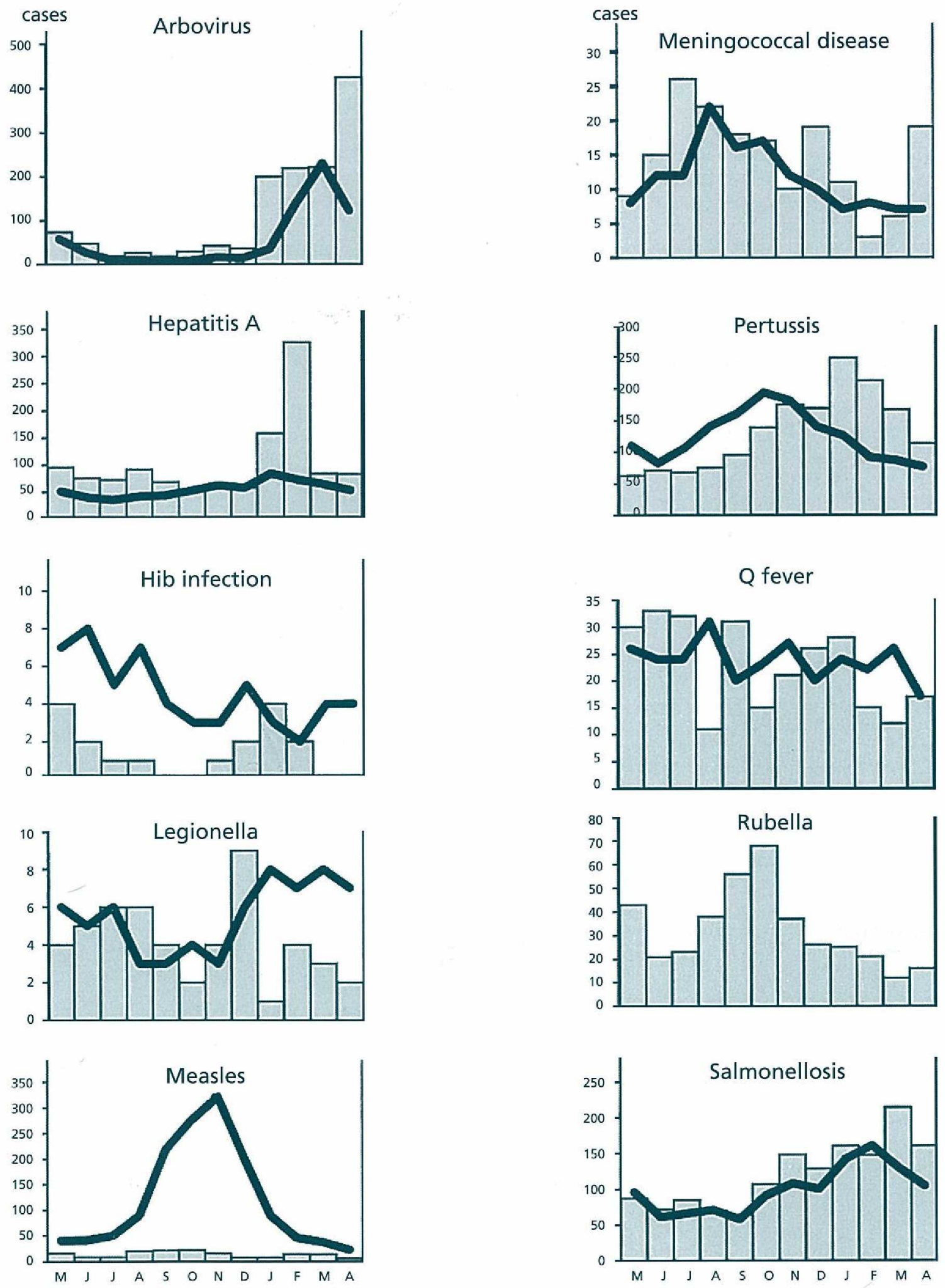

Because of data collation problems, historic rubella figures are unavailable. 
FIGURE 2

ROSS RIVER VIRUS INFECTIONS, NSW, NOTIFIED JAN - MAY 1997, BY HEALTH SERVICE AREA

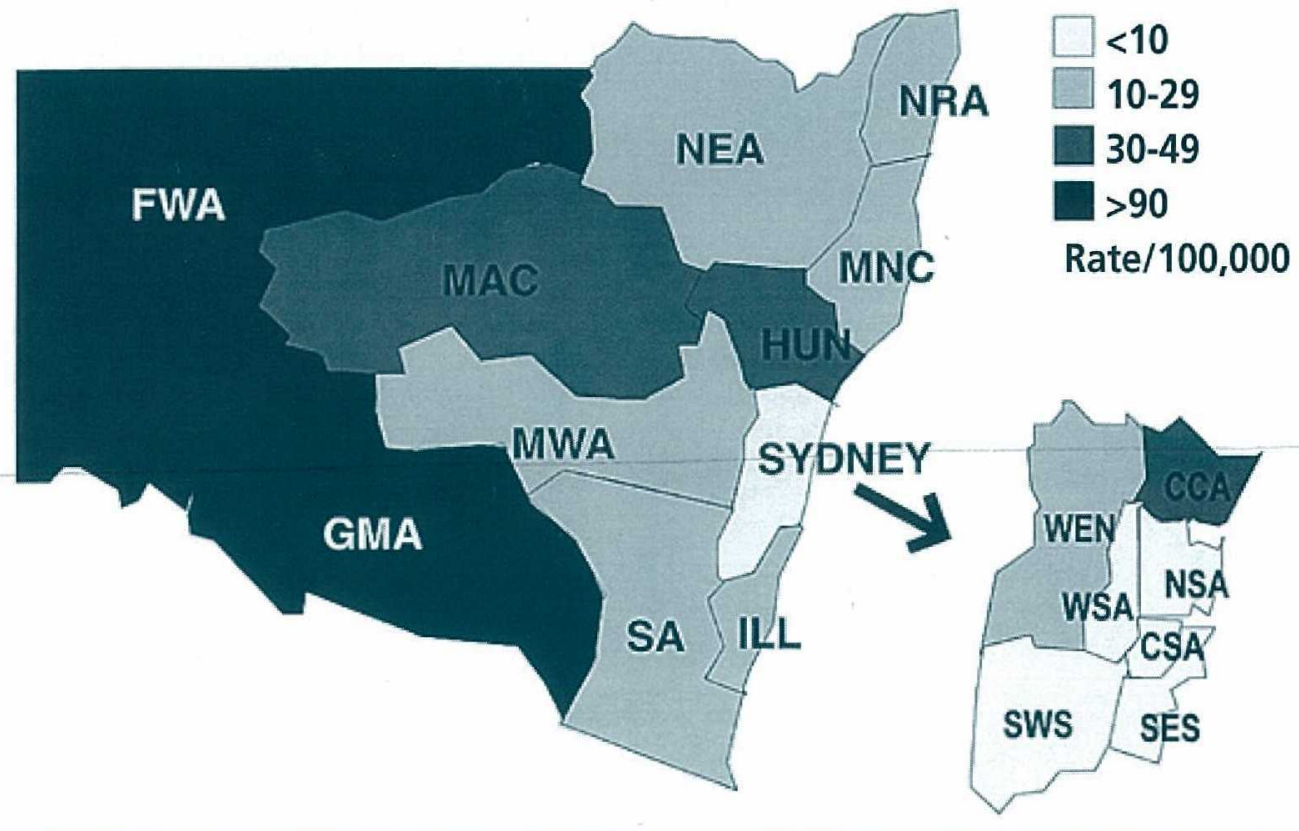

\section{Infectious diseases - June 1997}

\section{Continued from page 51}

During the 1996-97 northern hemisphere season, many countries reported moderate to severe influenza epidemics. Activity peaked in Western Europe and North America in December 1996 or January 1997, and began in Central and Eastern Europe in mid-January.

Reports of influenza-like illness from the NSW Sentinel GP Surveillance Scheme are received through five Public Health Units, and include data from 5-64 doctors who consult 732-7,411 patients each week. These data show that the rates of influenza-like illness so far in 1997 are similar to (or slightly down on) the same period last year (Figure 3 ).

Four sentinel hospitals (Prince of Wales, Westmead, New Children's and Liverpool) reported a mixture of influenza A (29) and B (20) cases identified through virology and serology so far in 1997 (Figure 4).

1. Guidelines for the control of meningococcal disease in Australia. Canberra: National Health and Medical Research Council. Available from the Publications Officer, NHMRC, MDP 50, GPO Box 9848 , Canberra 2601, telephone (02) 62897646 , facsimile (02) 62898776

\section{FIGURE 3}

NSW GP SENTINEL SURVEILLANCE

Influenza-like illness 1997 by week of consultation with historical comparisons

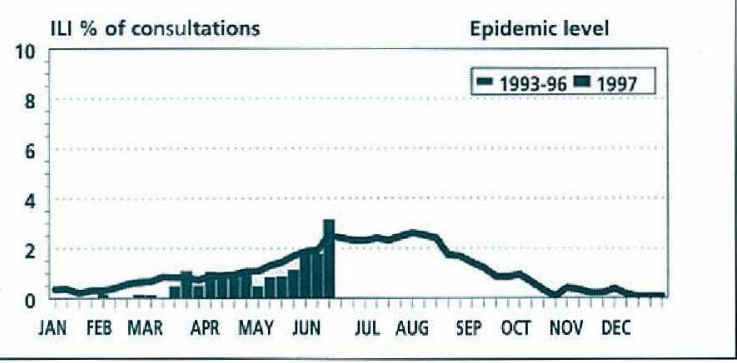

\section{FIGURE 4}

LABORATORY REPORTS OF INFLUENZA, NSW 1 JANUARY-29 JUNE 1997

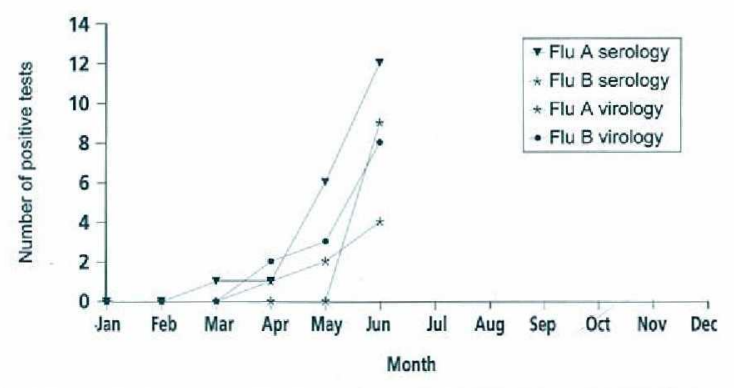




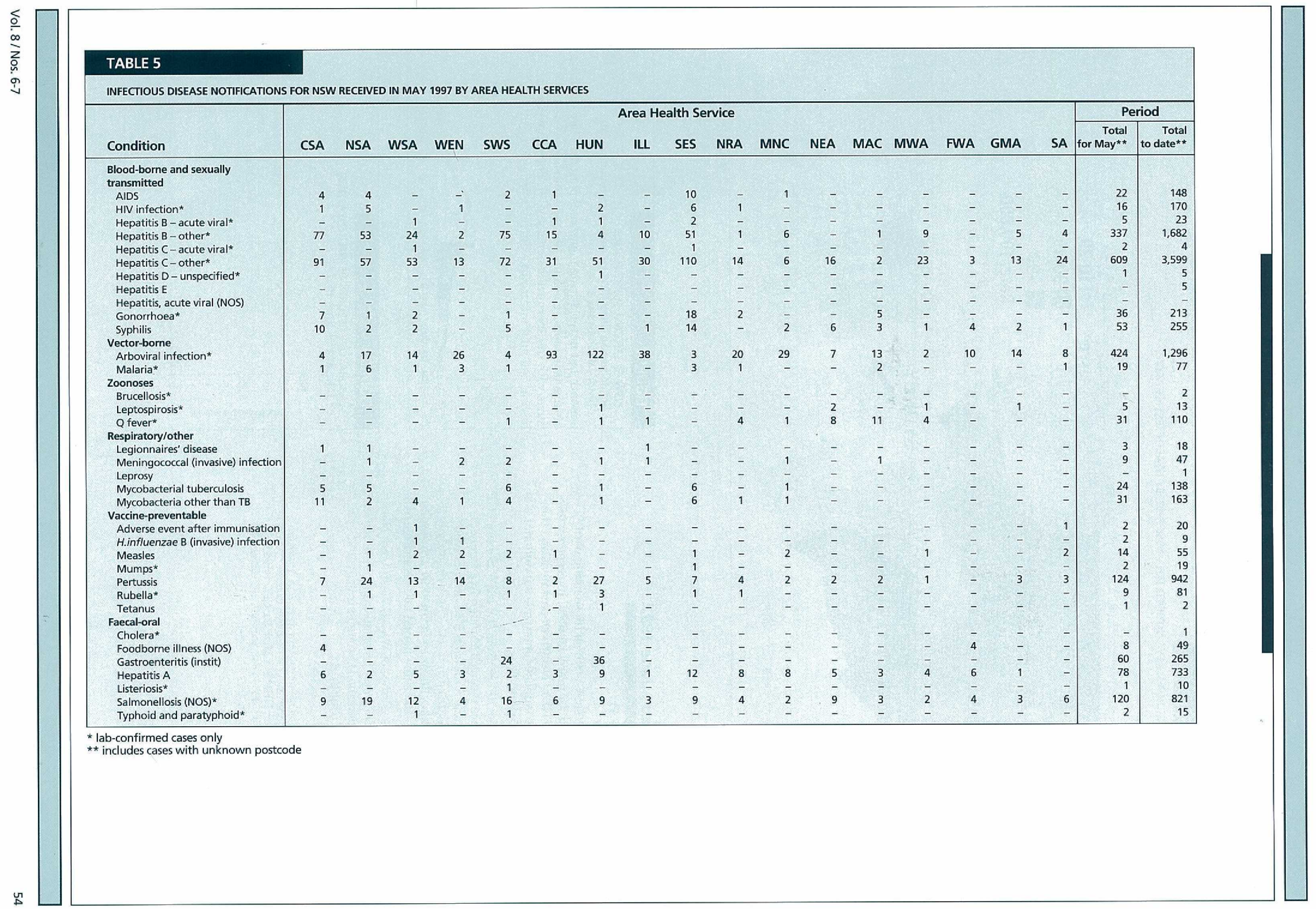




\section{INFECTIOUS DISEASES - JULY 1997}

\section{TRENDS}

$\mathrm{n}$ the 12 months to May 1997, almost 1,800 cases of pertussis were notified in NSW, including the deaths of four small babies (Figure 5). Pertussis is highly preventable through immunisation, yet immunisation rates in NSW remain too low - the 1995 Australian Bureau of Statistics household survey found that 38 per cent of children under 7 years of age were not fully immunised against pertussis. Pertussis rates for the period June 1996 to May 1997, by Health Area, are shown in Figure 6.

So far this year, there have been two cases of tetanus; the two patients were not up to date with their immunisations. The first case, a Sydney woman in her 70 s, was notified in January and reported having been scratched by a duck 10 days before admission. The second case, a Hunter Area woman in her 40 s, was notified in May, and reported having scratched her leg two weeks before admission to hospital. These two highly preventable cases highlight the importance of doctors routinely (and opportunistically) checking and immunising all adults against tetanus and diphtheria each 10 years.

Reports of arbovirus infections remained elevated in May and June. Summer rains around the more populous part of the coast of NSW helped make 1997 a record year for these infections, with 1,590 cases reported to the end of June.

Measles reports also have risen (Figure 5), particularly in the Western sector of Sydney (Table 6).

\section{CRYPTOSPORIDIUM AND SYDNEY WATER}

In early July, Sydney Water Corporation reported that it had detected small numbers of Cryptosporidium oocysts in treated water late in June and early in July.

Cryptosporidium infection causes an illness lasting several days characterised by 8 to 10 episodes of watery diarrhoea per day, abdominal cramps, fever and vomiting. In people who are immunosuppressed, such as those living with AIDS, infection can last for many months. In response to the water findings, the NSW Health Department and the Public Health Network launched intensive surveillance for diarrhoeal disease and cryptosporidiosis through laboratories, emergency departments, general practitioners and pharmacies throughout Sydney. No evidence of disease attributable to Cryptosporidium in drinking water was detected. However, because the HIV-affected community and other sectors of the public have expressed interest in such findings in the past, Sydney Water Corporation released testing details on 17 July.

\section{INFLUENZA SURVEILLANCE}

There has been a sharp increase in laboratory isolates of influenza A in July (Figure 7). Between 1 July and 27 July, sentinel laboratories reported 95 diagnoses of influenza $\mathrm{A}$ infections and 33 of influenza B infections.

Reports of influenza-like illness from the NSW Sentinel GP Surveillance Scheme are received from five PHUs. Participating GPs report similar rates of influenza-like illness among their patients as previous years ( 2 per cent), although there was a slight increase in late June (Figure 8).
TRANSIMISSION OF HIV POSSIBLY ASSOCIATED WITH EXPOSURE OF MUCOUS MEMBRANE TO CONTAMINATED BLOOD - UNITED STATES

In February 1996 transmission of human immunodeficiency virus (HIV) by an unknown route involving an HIV-infected man and his previously uninfected female partner was reported to the United States Centers for Disease Control and Prevention (CDC). This report summarises the epidemiologic investigation of this incident, which suggests the woman was infected through the exposure of mucous membranes to contaminated blood.

In 1992 the HIV-infected man and his uninfected female partner were enrolled in a study in which couples with one HIV-infected partner and one non-HIV-infected partner were extensively counselled, administered questionnaires, and tested periodically for HIV infection. Blood drawn from the woman on 19 July, 1994 was HIV-negative by both enzyme immunoassay (EIA) and polymerase chain reaction (PCR). However, serum specimens obtained from the woman on 24 July, 1995 and 11 September, 1995 were positive by both EIA and immunofluorescent assay.

During the interval from the month before her last HIV-negative test (June 1994) to the month of her first HIV-positive test (July 1995), the woman denied known risk exposures for HIV (other sexual partners; non-injecting or injecting drug use; sexually transmitted diseases; blood transfusion; artificial insemination; occupational exposure to HIV; and acupuncture, tattoos, body piercing or other percutaneous injections). The sources of information obtained separately from each partner by two independent interviewers during this investigation and by interview records obtained dưring the study before the couple was aware of the HIV transmission were consistent regarding the couple's sexual practices between June 1994 and July 1995. During this period, the woman and her partner reported having vaginal intercourse an average of six times a month but never during menstrual periods. They reported always using latex condoms (for men) during sex, most times with the spermicide nonoxynol-9. The couple denied having had anal intercourse during this period. Although they reported a condom breakage that occurred in January 1994, both independently denied awareness of condom breakage or slippage between June 1994 and July 1995 and believed the condom remained in place each time while the penis was withdrawn.

The couple engaged in "deep kissing" (open-mouth to openmouth) several times a month. The man indicated that his gums frequently bled after he brushed and flossed his teeth and that the couple generally engaged in sexual intercourse and "deep kissing" at night after he brushed his teeth. Occasional instances of oral intercourse between the couple reportedly did not involve the exchange of semen or blood. In addition, the woman recalled using the man's toothbrush and razor, both without visible blood, on one occasion each. 


\section{FIGURE 5}

REPORTS OF SELECTED INFECTIOUS DISEASES, NSW, 12 MONTHS TO MAY 1997, BY MONTH OF ONSET (WITH HISTORICAL COMPARISON)
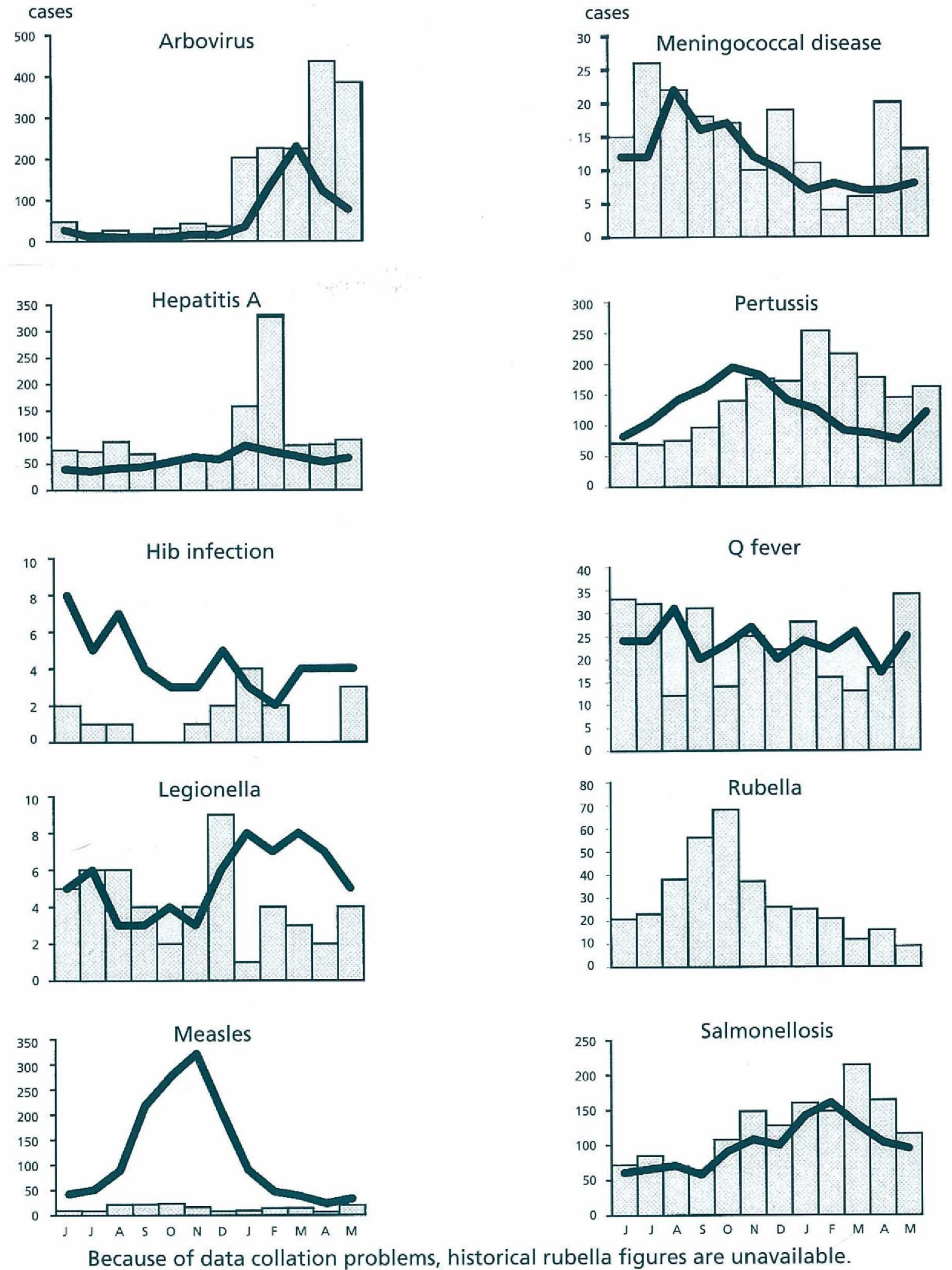

Because of data collation problems, historical rubella figures are unavailable. 
FIGURE 6

PERTUSSIS RATES, NSW, JUNE 1996 - MAY 1997

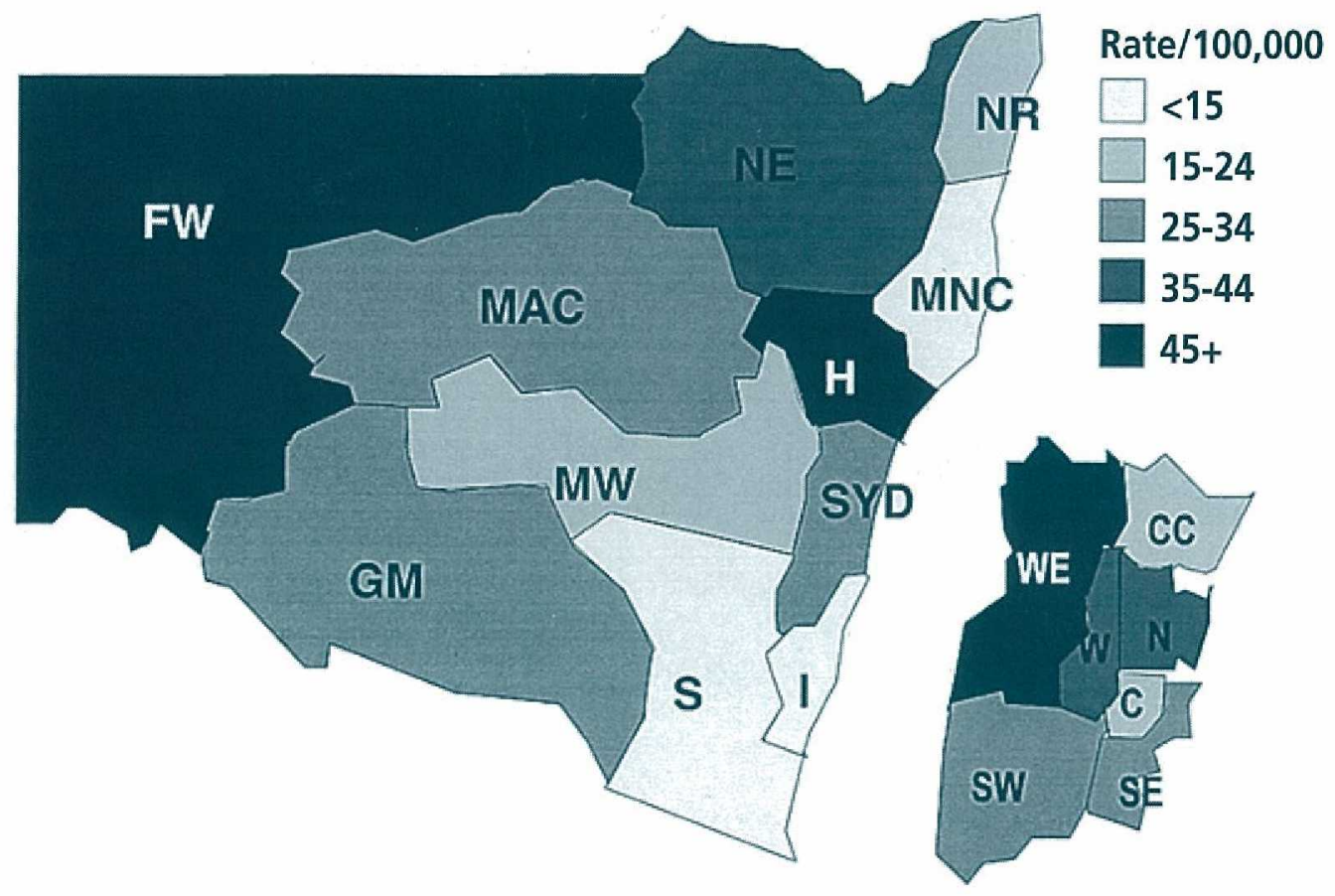

\section{FIGURE 7}

Influenza diagnoses by sentinel NSW laboratories, 1 January to 30 July 1997, by diagnostic method

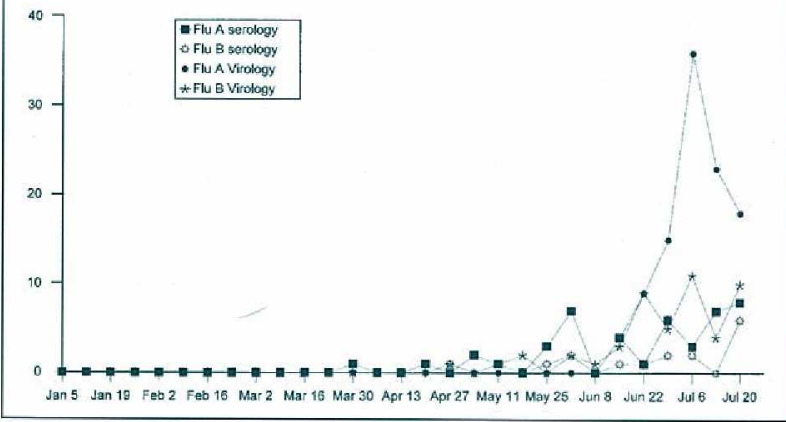

\section{FIGURE 8}

Proportion of consultations for influenza-like illness by NSW sentinel general practitioners, 1 January to 27 July 1997 (columns), by week, with historical comparison (line)

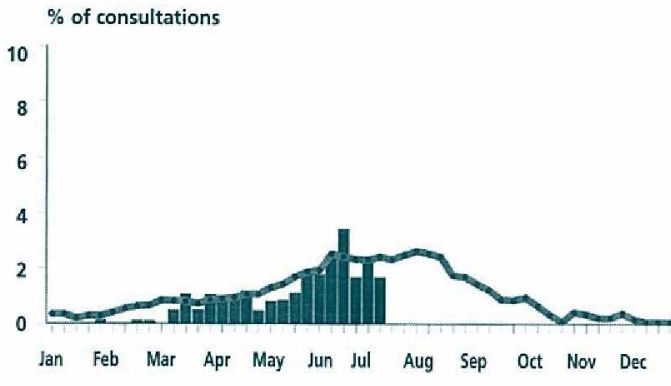

\section{Infectious diseases - July 1997}

\section{Continued from page 55}

She was unable to specify whether these events occurred during the putative infection period of June 1994 to July 1995.

The man had been infected with HIV since 1988 as the result of injecting drug use. He reported longstanding poor dentition and occasional sores in his mouth. On 29 August, 1994 he had a normal platelet count and a CD4+

T-lymphocyte count of 110 cells/mL. On September 6, 1994 he sought medical care at a clinic because of a cough, stress and intermittent weight loss. At this time small vesicles were noted in his throat. At a follow-up visit in April 1995 canker sores, halitosis and gingivitis were noted. In May 1995 , at his first dental visit since 1988, gingivitis and oral hairy leukoplakia were diagnosed. He had never received antiretroviral medication.

On 8 August, 1994 the woman underwent a dental evaluation followed by root canal therapy. Her dental records noted poor condition of gums, $2 \mathrm{~mm}$ to $6 \mathrm{~mm}$ pockets (indicating periodontitis), poor personal dental hygiene practices and a recommendation for periodontal therapy. No complications or excessive bleeding from the endodontic therapy were reported by the woman or noted by the dentist. The dentist was tested for HIV in May 1996 and was negative by EIA.

On 26 August, 1994 the woman experienced the onset of a syndrome that lasted 7-10 days and was characterised by fever of $39^{\circ} \mathrm{C}$, headache, swollen lymph nodes, sore neck and back and muscle aches in her legs. On 2 September she sought medical care from her primary-care physician, who noted erythema and inflammation of the gingiva. 


\section{Infectious diseases - July 1997}

\section{$\checkmark$ Continued from page 57}

The physician diagnosed a viral process with concomitant gum infection and prescribed erythromycin for treatment. The woman reported no other clinically important illness from June 1994 to July 1995.

Blood samples were obtained from both HIV-infected partners in April 1996. PCR techniques and sequencing indicated a high degree of relatedness between the viruses infecting the man and woman, supporting the conclusion that HIV was transmitted from one to the other. Testing of stored samples obtained from each partner in 1995 produced similar results.

\section{Comment}

This report suggests that the woman probably became infected with HIV between June 1994 and July 1995, as these symptoms were consistent with acute retroviral syndrome ${ }^{1}$. In addition, during June 1994 and July 1995, the man's CD4+ T-lymphocyte count was low, which may be associated with increased infectivity and risk for transmission ${ }^{2}$.

Results of the DNA sequencing and phylogenetic analysis support the epidemiologic findings that the woman's infection was acquired from her infected male partner. Although the exact route of transmission in this report cannot be determined, the most likely possibility is that the woman became infected through mucous membrane exposure to the man's saliva that was contaminated by blood from his bleeding gums or exudate from undetected oral lesions. Such exposure may have occurred during "deep kissing". The woman's inflamed gingival mucosa, as indicated by her dental and medical records, might have been a contributing factor.

Exposure to saliva uncontaminated with blood is considered to be a rare mode of HIV transmission for at least five reasons:

1) saliva inhibits HIV-1 infectivity ${ }^{3}$

2) HIV is infrequently isolated from saliva ${ }^{4}$

3) none of the approximately 500,000 cases of AIDS reported to $\mathrm{CDC}$ has been attributed to exposure to saliva

4) levels of HIV are low in the saliva of HIV-infected persons, even in the presence of periodontal disease ${ }^{5}$

5) transmission of HIV in association with kissing has not been documented in studies of non-sexual household contacts of HIV-infected people ${ }^{6}$. However, rare biterelated instances of HIV transmission from exposure to saliva contaminated with HIV-infected blood have been reported $^{7,8}$.
Other exposures of the woman to the man's blood or semen cannot be excluded. Although occasional instances of oral sex did not reportedly involve the exchange of semen or blood between the people in this report, these routes of transmission cannot definitively be excluded. Sexual exposure through vaginal intercourse is a plausible mechanism of transmission for the case described in this report; however, other studies of couples in which one partner is HIV-infected and the other is not indicate that HIV transmission is rare when heterosexual couples use condoms consistently during vaginal intercourse ${ }^{9}$. If a condom is not used correctly, it may slip off or break, thereby reducing its effectiveness as a barrier to HIV. However, both partners could not recall any instances of condom slippage or breakage during the time infection was likely to have occurred. In addition, although the shared use of a toothbrush or razor are theoretically plausible routes of transmission, the woman recalled that each event occurred only once, and she could not specify whether either event occurred during the period when transmission was most likely to have occurred.

The findings of this investigation underscore the multiple routes by which exposure to infectious body fluids can occur among sexually intimate people. Uninfected people considering intimate relationships with people known to be infected with HIV should be educated about the rare possibility of HIV transmission through mucous membrane exposures. People choosing to have sex with HIV-infected people or people with unknown HIV serostatus should correctly use latex condoms (for men) during each act of intercourse and should avoid any other exposure to potentially infectious body fluids, including blood, semen, or any other body fluid visibly contaminated with blood.

Adapted from: CDC. Transmission of HIV possibly associated with exposure of mucous membrane to contaminated blood. MMWR 1997; 46:620-624

1. Schacker T, Collier AC, Hughes J, Shea T, Corey L. Clinical and epidemiologic features of primary HIV infection. Ann Intern Med 1996; 125:257-64.

2. Laga M, Taelman H, Van der Stuyft P, Bonneux L, Vercauteren G, Piot P. Advanced immuno-deficiency as a risk factor for heterosexual transmission of HIV. AIDS $1989 ; 3: 361-6$.

3. Yeh CK, Handelman B, Fox PC, Baum BJ. Further studies of salivary inhibition of HIV-1 infectivity. J Acquir Immune Defic Syndr 1992; 5:898-903.

4. Ho DD, Byington RE, Schooley RT, Flynn T, Rota TR, Hirsch MS. Infrequency of isolation of HTLV-III virus from saliva in AIDS. N Engl I Med 1985; 313:1606.

5. Yeung SC, Kazazi F, Randle CG et al. Patients infected with human immunodeficiency virus type 1 have low levels of virus in saliva even in the presence of periodontal disease. J Infect Dis 1993; 167:803-9. 6. Rorers MF. White CR Sanders $R$ et al. Lack of transmission of human immunodeficiency virus from infected children to their household contacts. Pediatrics 1990; 85:210-4.

7. Vidmar L, Poljak M, Tomazic J, Seme K, Klavs I. Transmission of HIV-1 by human bite. Lancet $1996 ; 347: 1762-3$.

8. Anonymous. Notes and news: transmission of HIV by human bite. Lancet 1987; 2:522.

9. Saracco A, Musicco M, Nicolosi A et al. Man-to-woman sexual transmission of HIV: longitudinal study of 343 steady partners of infected men. J Acquir Immune Defic Syndr 1993; 6:497-502. 


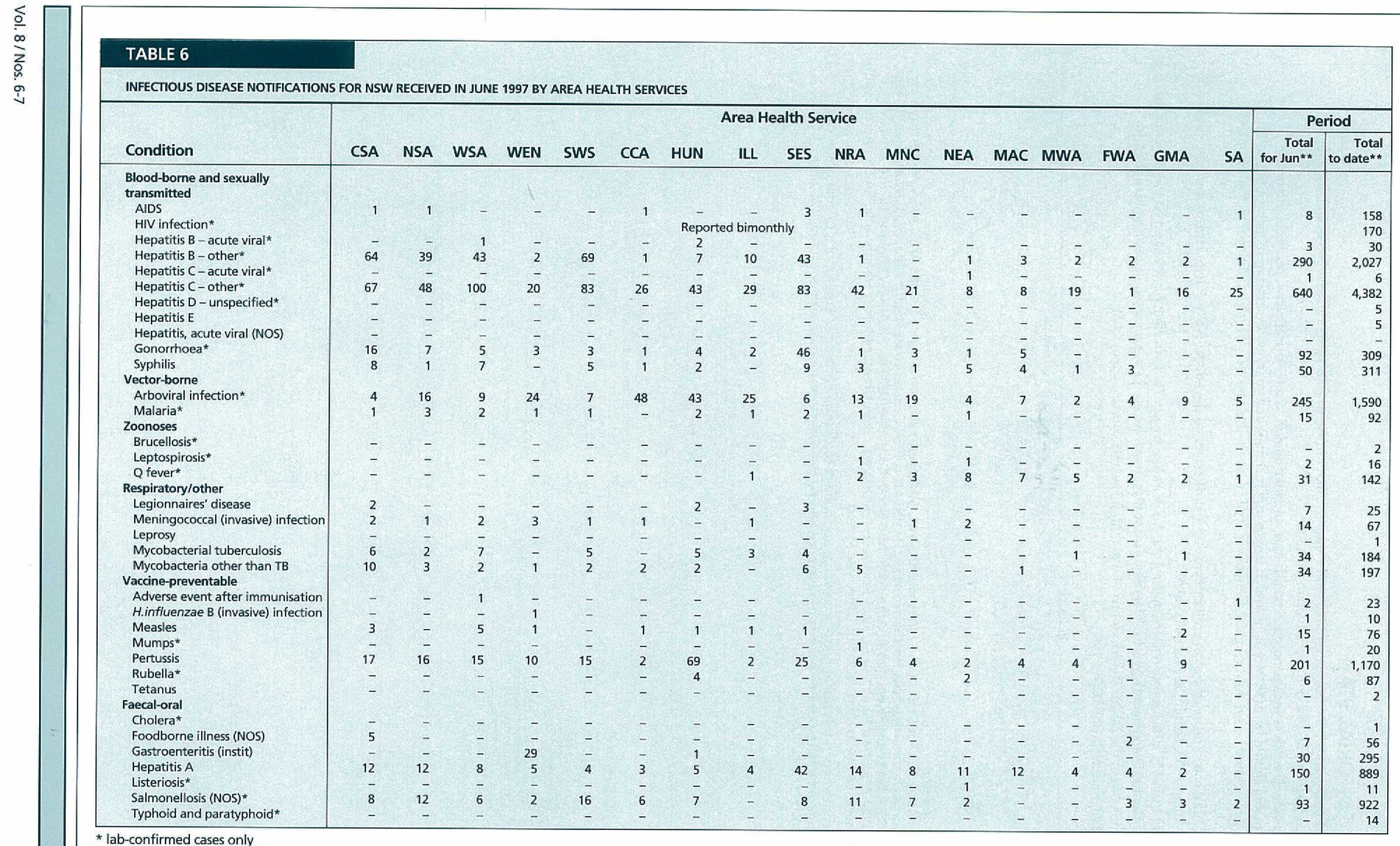

* lab-confirmed cases only 


\section{PUBLIC HEALTH EDITORIAL STAFF}

The editor of the NSW Public Health Bulletin is Dr Michael Frommer, Director, Centre for Research and Development, NSW Health Department. Dr Lynne Madden is production manager.

The Bulletin aims to provide its readers with population health data and information to motivate effective public health action. Articles, news and comments should be 1,000 words or less in length and include a summary of the key points to be made in the first paragraph. References should be set out using the Vancouver style, described in the New England Journal of Medicine 1997; 336:309-315.

Please submit items in hard copy and on diskette, preferably using WordPerfect, to the editor, NSW Public Health Bulletin, Locked Mail Bag 961, North Sydney 2059. Facsimile (02) 93919029.

Please contact your local Public Health Unit to obtain copies of the NSW Public Health Bulletin. The Bulletin can be accessed via the Internet from the NSW Health Department's World Wide Website, at http:/www.health.nsw.gov.au/public-health/phb/phb.html Back issues can be obtained from the Better Health Centre, Locked Mail Bag 961, North Sydney 2059.

Telephone: (02) 9954 1193, Facsimile (02) 99555196.

Abbreviations used in this Bulletin:

CSA Central Sydney Health Area, SES South Eastern Sydney Health Area, SWS South Western Sydney Health Area, WSA Western Sydney Health Area, WEN Wentworth Health Area, NSA Northern Sydney Health Area, CCA Central Coast Health Area, ILL IIlawarra Health Area, HUN Hunter Health Area, NRA Northern Rivers Health Area, MNC Mid North Coast Health Area, NEA New England Health Area, MAC Macquarie Health Area, MWA Mid West Health Area, FWA Far West Health Area, GMA Greater Murray Health Area, SA Southern Health Area, OTH Interstate/Overseas, U/K Unknown, NOS Not Otherwise Stated.

Please note that the data contained in this Bulletin are provisional and subject to change because of late reports or changes in case classification. Data are tabulated where possible by area of residence and by the disease onset date and not simply the date of notification or receipt of such notification. 